\title{
A produção científica sobre Língua Brasileira de Sinais (Libras) presente nos currículos Lattes do CNPq
}

\author{
Simone Aparecida dos Santos
}

Marlene Oliveira

Graduação em Biblioteconomia pela UFMG. Mestre em Ciência da Informação pela UFMG. Especialista em Elaboração de Projetos de Políticas Públicas. Bibliotecária aposentada pela UFMG

Doutora pela Universidade de Brasília. Mestre pelo IBICT-RJ. Graduada em biblioteconomia pela FUOM/MG. Professora associada 4 da Escola de Ciência da Informação/UFMG

http://dx.doi.org/10.1590/1981-5344/2776

Análise da produção de artigos científicos sobre o tema Língua Brasileira de Sinais (Libras) no período de 1987 a 2014. A escolha do período ocorreu em função da comparação entre a produção de artigos sobre o tema antes e depois da promulgação da lei no 10.436/2002, que reconheceu a Língua Brasileira de Sinais (Libras) como meio de comunicação dos surdos. A metodologia adotada foi de cunho quantitativo, com a adoção de técnicas bibliométricas para medir a produção em Libras. A pesquisa teve como corpus de investigação a citada produção científica declarada pelos pesquisadores em seus respectivos currículos disponibilizados na Plataforma Lattes. Foram identificados 102 autores e 241 artigos de periódicos. Verificou-se um aumento de títulos de doutores após a promulgação da Lei de Libras. A produção de 241 artigos de periódicos foram produzidos por 102 autores. Os títulos de periódicos que mais publicaram artigos sobre Libras estão ligados à instituição especializada como o Instituto Nacional de Educação de Surdos (INES), Linguística, Estudos Linguísticos e Educação. Mesmo em uma temática com pouco tempo de existência constatou-se significativo crescimento na publicação de artigos sobre o tema, cerca de $417 \%$, após a promulgação da lei de Libras. Portanto, conclui-se que ocorreu um reflexo positivo para o desenvolvimento da área depois da promulgação da lei de Libras. 
Palavras-chave: Técnicas bibliométricas; Brasileira de Sinais (Libras); produção científica.

\section{The scientific production of Brazilian Sign Language (Libras) present in Lattes curriculum of CNPq}

The production of scientific papers on the subject Brazilian Sign Language (Libras) from 1987 to 2014 has been analysed. The timeframe was chosen due to the need to compare the articles published on the subject before and after the enactment of law No. 10.436 / 2002, which recognized the Brazilian Sign Language (Libras) as a means of communication of the deaf. The methodology used was quantitative, with the adoption of bibliometric techniques to measure production in pounds. The research was corpus investigation cited scientific production declared by the researchers in their respective curriculum available in the Lattes Platform. They identified 102 authors and 241 journal articles. Even in a subject with little time of existence found a significant increase in the publication of articles on the subject, about $417 \%$ after the enactment of Libras law. Therefore, it is concluded that there was a positive impact to the development of the area after the promulgation of the law.

Keywords: Bibliometric techniques; Brazilian Sign Language (Libras); Scientific production.

Recebido em 25.04.2016 Aceito em 12.07.2017

\section{Introdução}

A produção de resultados de pesquisa é o efeito principal da atividade científica. Conforme Ziman (1979) a publicação científica ascende o nível de conhecimento público quando o autor e seus relatos são reconhecidos e legitimados pela comunidade científica. A análise da produção científica tem sido estudada para medir o desenvolvimento científico de um país e de um campo científico e de uma instituição geradora de conhecimentos é usada para avaliação em agências de fomento e, também por universidades públicas para medir o desempenho de seus pesquisadores e de áreas científicas.

A produção científica de diferentes áreas e domínios tem sido objeto de pesquisa na Comunicação Científica e na Bibliometria. Conforme 
Taque-Sutcliffe (1992). A Bibliometria estuda os aspectos quantitativos da produção, disseminação e uso da informação registrada. Assim desenvolve padrões e modelos matemáticos para medir esses processos e usa os resultados para elaborar previsões e apoiar tomadas de decisões.

Neste artigo, à luz da comunicação científica utilizou-se técnicas bibliométricas para identificar a produção científica sobre a Língua Brasileira de Sinais (Libras), no período de 1987 a 2014, visando identificar o impacto da Lei n. 10.436 de 24 de abril de 2002 (BRASIL. Presidência da República, 2002), conhecida como Lei da Libras.

\section{A Comunicação científica, Bibliometria e estudos métricos}

A Comunicação científica é vista por Garvey (1979) como o coração da Ciência. Ela faz parte de todo o processo de construção de conhecimentos. O processo de publicação de conhecimentos (livros, artigos, comunicados em congressos) implica em maior ou menor grau na avaliação dos pares (ZIMAN,1979). Assim, a publicação científica é uma forma de reconhecer e legitimar autores e seus artigos.

Os estudos de produtividade científica na Comunicação Científica com o uso de técnicas bibliométricas tem se mostrado eficientes na análise de progressos em áreas, subáreas e na medição de autores e instituições.

Pritchard (1969) foi o primeiro autor a usar o termo Bibliometrics. Esse termo vem do termo Bibliometrie quando Paul Otlet ${ }^{1}$ pensou em construir um campo chamado Bibliologia, considerada uma ciência geral para compreender o conjunto sistemático dos dados relativos à produção, conservação, circulação e uso dos escritos e dos documentos de toda a espécie.

Para Alvarado (1984), no cenário brasileiro a Bibliometria foi introduzida por Saracevic, Boyce e Lancaster, sendo que o primeiro se destacou por ter orientado oito mestrandos no Instituto Brasileiro de Informação em Ciência e Tecnologia (IBICT). A Bibliometria é usada em muitas bases de dados bibliográficos para medir, avaliar e disseminar a produção científica.

Castro (2009) analisou a produção científica da Ciência da Informação no período de 1998 a 2006 e trouxe alguns resultados interessantes. Houve um visível crescimento de docentes/pesquisadores nos programas de Pós-Graduação em Ciência da Informação. Os artigos de periódicos na Ciência da Informação mostrou-se menor em relação a quantidade de artigos publicados em periódicos externos a área. Esse fato apontou que o número de títulos de periódicos na época era insuficiente para canalizar a produção científica da Ciência da Informação.

\footnotetext{
1 "Paul Marie Ghislain Otlet, advogado, nascido na Bélgica, em 23 de agosto de 1868. Foi um dos criadores do chamado Repertório Bibliográfico Universal (RBU). Em 1905, em parceria com La Fontaine, "publicou a Classificação Decimal Universal (CDU), configurada de tabelas de classificação do conhecimento desenvolvidas com base na já existente Classificação Decimal de Dewey (CDD), criada pelo bibliotecário inglês Melvil Dewey em 1876 (DEWEY, 2003)". (POZZATTI et al., 2014, p. 204).
} 
Alguns pesquisadores se destacaram, de acordo com Vanti (2002), pelos esforços despendidos para desenvolver leis e sua aplicação na Bibliometria: Lei de Lotka, Lei de Bradford e Lei de Zipf.

A Tabela 1 apresenta uma síntese com as especificidades dessas leis

\begin{tabular}{l|l}
\multicolumn{2}{c}{ A Tabela 1 - Leis da Bibliometria - síntese } \\
\hline \multicolumn{1}{c|}{ Leis } & \multicolumn{1}{c}{ Especificidades } \\
Lei de Bradford ou Lei & $\begin{array}{l}\text { grau de relevância de periódicos em uma área do conhecimento; o } \\
\text { "núcleo de periódicos", aquelas que mais produzem sobre o tema. }\end{array}$ \\
\hline $\begin{array}{l}\text { Lei de Lotka ou Lei do } \\
\text { Quadrado Inverso }\end{array}$ & $\begin{array}{l}\text { considera que alguns pesquisadores, supostamente de maior } \\
\text { prestígio em uma área do conhecimento, produzem muito e muitos } \\
\text { pesquisadores, supostamente de menor prestígio, produzem pouco. }\end{array}$ \\
\hline $\begin{array}{l}\text { Leis de Zip ou Lei do } \\
\text { Mínimo Esforço }\end{array}$ & $\begin{array}{l}\text { estima as frequências de ocorrência das palavras em textos } \\
\text { científicos e tecnológicos, delimitando a região de concentração de } \\
\text { termos de indexação; verifica que um pequeno grupo de palavras } \\
\text { ocorre muitas vezes e um grande número de palavras é de pequena } \\
\text { frequência. }\end{array}$ \\
\hline
\end{tabular}

Fonte: Adaptado de GUEDES (2012, p. 81).

A Bibliometria permite o estudo de citações, índice $h$, estudo de coautoria e outros. Conforme Guedes (2012) a Bibliometria contribui para tomadas de decisão na gestão da informação e do conhecimento, uma vez que auxilia na organização e sistematização de informações científicas e tecnológicas.

\section{Lingua Brasileira de Sinais: LIBRAS}

De acordo com Nogueira e Zanquetta (2008, p. 224) a definição do nome para identificar a linguagem dos surdos ocorreu em 1993. Na ocasião, a denominação Língua Brasileira de Sinais "foi estabelecida em Assembleia, convocada pela Federação Nacional de Educação e Integração dos Surdos (FENEIS)". Posteriormente essa nomenclatura foi retificada pela legislação brasileira em 24 de abril de 2002, que em seu "Art. $1^{\circ}$ ́ É reconhecida como meio legal de comunicação e expressão a Língua Brasileira de Sinais - Libras e outros recursos de expressão a ela associados" (BRASIL. Presidência da República, 2002). Nesse cenário a Lei no 10.436, conceitua Língua Brasileira de Sinais (Libras), como:

[...] forma de comunicação e expressão, em que o sistema linguístico de natureza visual-motora, com estrutura gramatical própria, constituem um sistema linguístico de transmissão de ideias e fatos, oriundos de comunidades de pessoas surdas do Brasil (BRASIL. Presidência da República, 2002).

A repercussão social, para Santana e Bergamo (2005), foi dos aspectos mais relevantes no reconhecimento da Libras como língua dos surdos, em razão da legitimação do surdo como sujeito de linguagem, com todas as funcionalidades contidas na linguagem: comunicação, pensamento, aprendizagem. 


\section{Procedimentos metodológicos}

A pesquisa teve como corpus de investigação a produção científica declarada pelos pesquisadores na Plataforma Lattes, mantida pelo Conselho Nacional de Desenvolvimento Científico e Tecnológico (CNPq) sobre o tema Língua Brasileira de Sinais (Libras).

\subsection{Procedimentos de coleta dos dados}

A partir de uma amostra de currículos recuperados foram selecionados artigos que posteriormente foram compilados em uma base de dados em que foram extraído os dados: Autoria, Titulo do artigo, Data, Título do periódico, Editor, Área/escopo da revista.

\subsection{Procedimentos de análise dos dados}

Para analisar os dados foram utilizadas as seguintes categorias:

a) Nome do pesquisador;

b) Formação acadêmica do autor;

c) Instituição de afiliação do autor;

d) Tipo de publicação;

e) Identificação do artigo;

f) Identificação do periódico científico.

Para verificar o impacto da Lei da Libras na produção científica sobre - tema Libras, foi identificada a produção nos anos anteriores e posteriores à promulgação da referida Lei. Ao todo foi analisada a produção sobre o tema de 1987 a 2014. Assim, realizou-se uma comparação entre os dois períodos.

\section{Resultados}

\subsection{Formação acadêmica dos autores}

A primeira análise realizada foi a respeito da formação dos autores dos artigos. A formação em nível de doutorado está descrito a seguir.

A formação de doutores e suas pesquisas estão arrolados no Grafico 1, a seguir:

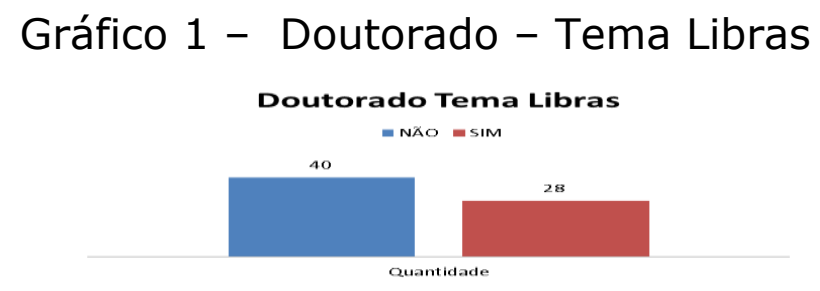

Fonte: Dados da pesquisa. 
Entre os pesquisadores 68 concluíram o doutorado. Desse total verificou-se a defesa de 28 teses o que corresponde a $41,2 \%$ sobre a temática Libras. As demais 40 teses ou $58,8 \%$ versavam sobre outros temas.

Para identificar a tendência de aumento na titulação de doutor após a promulgação da Lei da Libras ocorrida em 2002, foram analisadas as teses defendidas nos períodos anteriores e posteriores à legislação.

Esta análise foi representada no Gráfico 2.

Gráfico 2 - Ano da titulação doutorado

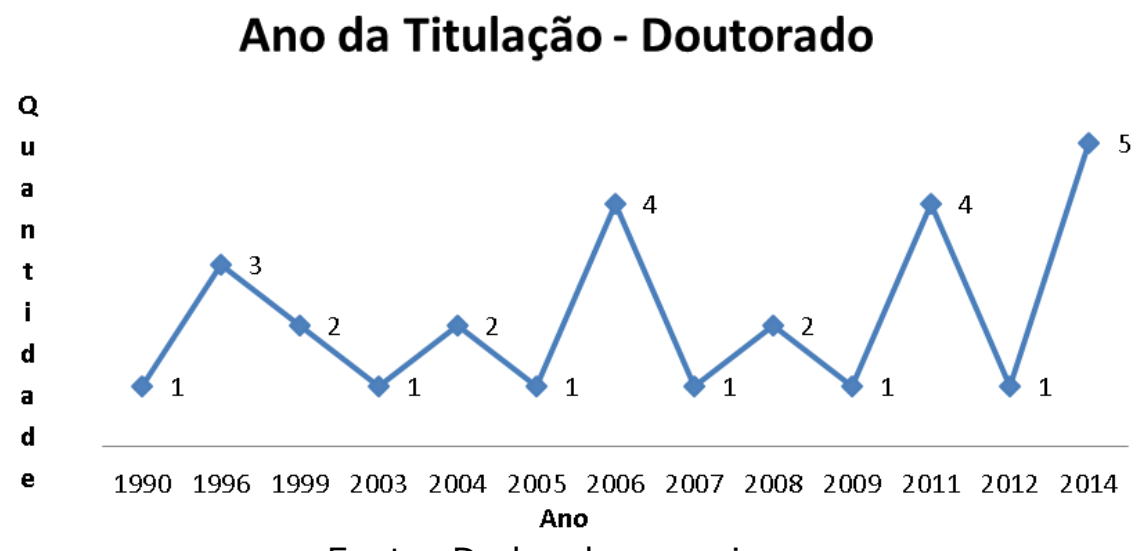

Fonte: Dados da pesquisa.

Nesse período foram defendidas 28 teses, sendo que nos anos anteriores à promulgação da lei foram defendidas 6 teses como marca o ano de 2003. Nos anos posteriores foram defendidas 22. Observa-se um aumento de $266 \%$ no número de doutoramentos sobre o tema Libras, o que sugere que a lei possa ter influenciado positivamente os pesquisadores ligados ao tema.

\subsection{Produção científica de artigos de periódicos sobre Libras}

Foram levantados e identificados 101 currículos na Plataforma Lattes sendo que 28 não foram incluídos nessa etapa de análise da produção científica. A produção desses pesquisadores estava relacionada a apresentação de trabalhos em eventos ou a publicação de capítulos e títulos de livros. Esta produção não foi objeto de estudo dessa pesquisa.

O levantamento dos currículos restante (73 pesquisadores) foram considerados nesta fase da pesquisa. A análise da produção científica dos mesmos totalizou 241 artigos sobre Libras, produzidos por 102 autores. Para proceder a análise de cada um deles, optou-se por buscar entre a autoria do artigo, o autor citado em primeiro lugar, que nesta pesquisa foi tratado como autor principal

Os artigos foram publicados em 131 títulos de periódicos no período analisado. 3.

A distribuição de artigos em periódicos está apresentada no Gráfico 
Gráfico 3 - Frequência de publicação sobre o tema Libras por periódico

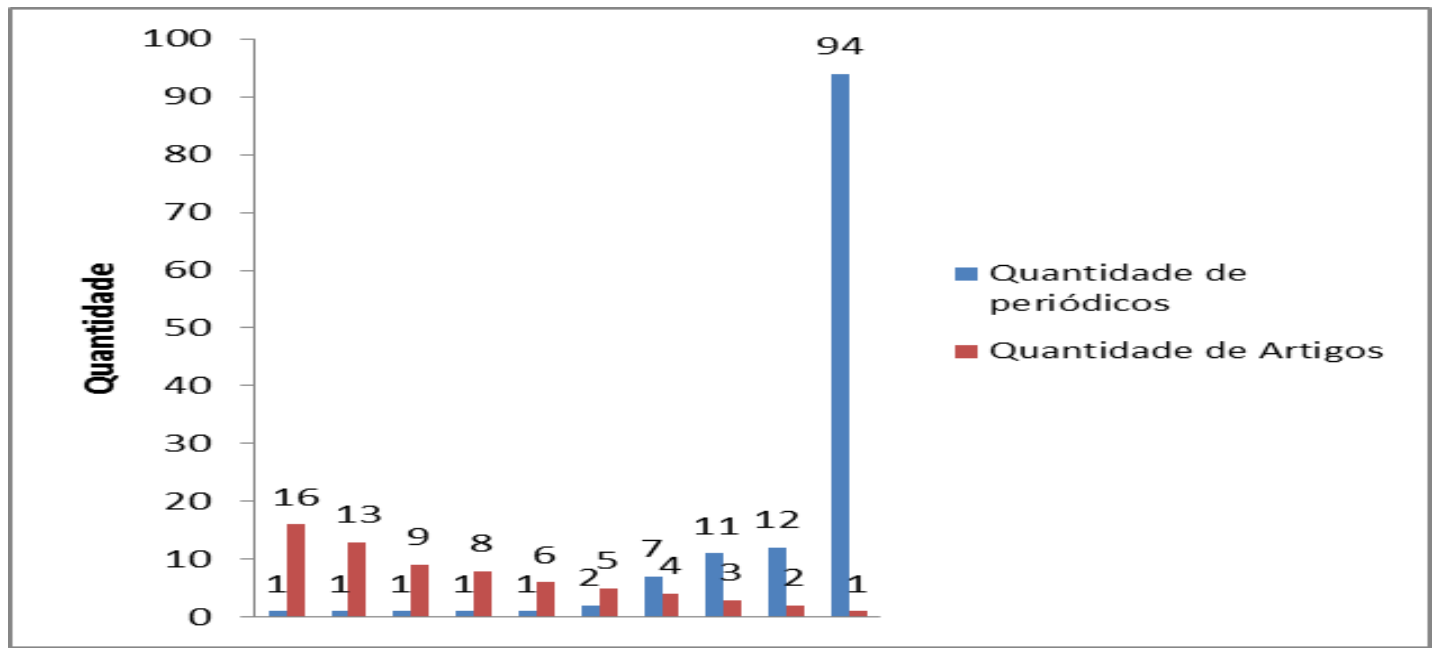

Fonte: Dados da pesquisa.

Na amostra de 131 periódicos, 94 publicaram apenas um artigo e dois periódicos publicaram mais de 10 artigos. Verifica-se também que apenas quatro títulos publicaram 46 artigos.

A concentração de publicações em alguns periódicos pode ser analisada segundo a Lei de Bradford. Essa Lei sugere que

[...] na medida em que os primeiros artigos sobre um novo assunto são produzidos, eles são submetidos a uma pequena seleção, por periódicos apropriados, e são aceitos. Esses periódicos, inicialmente selecionados, atraem mais e mais artigos, no decorrer do desenvolvimento da área de assunto. Porém, ao mesmo tempo, outros periódicos começam a publicar seus primeiros artigos sobre o assunto. Se o assunto continua a se desenvolver, emerge eventualmente um núcleo de periódicos mais produtivos, no que se refere à edição de artigos sobre o assunto (GUEDES, 2012, p. 82).

Esse tipo de análise adotado por Bradford possibilitou "a ordenação de periódicos segundo zonas de produtividade decrescente de artigos" (GUEDES, 2012, p. 82).

Em um tema com mais tradição de pesquisa o primeiro núcleo de periódico é composto por títulos que publicam muito sobre o tema. Esse é seguido por outro núcleo com periódicos que publicam menos e assim por diante. Assim é possível verificar a dispersão da literatura sobre o tema em um conjunto de periódicos.

A temática Libras pode ser considerada uma temática ainda recente e, por isso não carrega ainda um comportamento de comunicação formal como outras áreas mais estruturadas. Contudo já é possível perceber periódicos que estão publicando uma quantidade bem maior de artigos que a maioria dos periódicos.

2.

A distribuição de artigos por autor principal foi explicitada na Tabela 
Tabela 2 - Distribuição de artigos por autor principal.

\begin{tabular}{c|c|c}
\hline Quantidade de autores & $\begin{array}{c}\text { Quantidade de Artigos } \\
\text { publicados }\end{array}$ & Total de Artigos \\
\hline \hline 1 & 18 & 18 \\
\hline 1 & 17 & 17 \\
\hline 1 & 7 & 7 \\
\hline 2 & 3 & 6 \\
\hline 3 & 10 & 20 \\
\hline 4 & 5 & 20 \\
\hline 5 & 4 & 36 \\
\hline 6 & 6 & 16 \\
\hline 8 & 2 & 71 \\
\hline 71 & 1 & Total de artigos: 241 \\
\hline Total de autores: 102 & &
\end{tabular}

Fonte: Dados da pesquisa.

Verifica-se que 12 autores principais produziram 98 artigos do total da produção científica em Libras que foi de 241, ou seja, 40,66\% do total. Esse grupo representa os autores mais produtivos. Essa tendência se aproxima da Lei de Lotka que preconiza "que alguns pesquisadores, supostamente de maior prestígio em uma área do conhecimento, produzem muito e muitos pesquisadores, supostamente de menor prestígio, produzem pouco" (GUEDES, 2012, p. 81).

A Tabela 3 apresenta a distribuição de número de artigos por títulos de periódicos.

Tabela 3 - Periódicos com taxa de publicação $\geq 5$ artigos

\begin{tabular}{c|c|c}
\hline Ordem & Título/Periódicos & $\mathbf{N}^{\mathbf{0}}$ Artigos \\
\hline \hline 1 & Espaço & 16 \\
\hline 2 & Letras de Hoje & 13 \\
\hline 3 & Revista Virtual de Estudos da Linguagem - ReVEL & 9 \\
\hline 4 & ETD: Educação Temática Digital & 8 \\
\hline 5 & Arqueiro & 6 \\
\hline 6 & Cadernos de Tradução & 5 \\
\hline 7 & Revista Brasileira de Linguística Aplicada & 5 \\
\hline
\end{tabular}

Fonte: Dados da pesquisa.

O periódico "Espaço", publicado pelo Instituto Nacional de Educação de Surdos (INES), foi o que recebeu o maior número de artigos entre os periódicos. Os sete periódicos que publicaram um total $\geq 5$ artigos são responsáveis por $26 \%$ da produção o que corresponde a $1 / 4$ das publicações.

A identificação do escopo, ou área em que se inserem os periódicos mais produtivos está representada na Tabela 4. 
Tabela 4 - Escopo/Área

\begin{tabular}{c|c|c|c}
\hline Ordem & Título/Periódicos & $\mathbf{N}^{\mathbf{0}}$ artigos & Escopo/Área \\
\hline \hline 1 & Espaço & 16 & Educação Especial/Surdez \\
\hline 2 & Letras de Hoje & 13 & Linguística \\
\hline 3 & $\begin{array}{c}\text { Revista Virtual de Estudos da } \\
\text { Linguagem - ReVEL }\end{array}$ & 9 & Estudos Linguísticos \\
\hline 4 & ETD: Educação Temática Digital & 8 & Educação \\
\hline 5 & Arqueiro & 6 & Educação Especial/Surdez \\
\hline 6 & Cadernos de Tradução & 5 & Estudos da Tradução \\
\hline 7 & $\begin{array}{c}\text { Revista Brasileira de Linguística } \\
\text { Aplicada }\end{array}$ & 5 & Linguística \\
\hline
\end{tabular}

Fonte: Dados da pesquisa.

Observa-se que as áreas com maior incidência são Linguística, Educação Especial, e Educação, com respectivamente 27, 22 e 8 artigos cada. Linguística, Educação Especial e Educação, estão inseridas nas grandes áreas do CNPq Linguística, Letras e Artes e Ciências Humana. Essa mesma situação ocorreu durante a análise das grandes áreas predominantes nas teses defendidas. Este achado sugere que estas duas áreas estão se consolidando como as mais envolvidas com o tema Libras, o que pode estar relacionado as profissões que estão nestas áreas.

As distribuições das instituições editoras desses periódicos por região estão representadas na Tabela 5.

Tabela 5 - Distribuição de artigos por Instituição e por Região

\begin{tabular}{c|c|c}
\hline $\mathbf{N}^{\mathbf{0}}$ Artigos & Instituição & Região \\
\hline \hline 16 & INES & Sudeste \\
\hline 13 & PUCRJ; Unb; USP & Não se aplica \\
\hline 9 & Independente & Não se aplica \\
\hline 8 & UNICAMP & Sudeste \\
\hline 6 & INES & Sudeste \\
\hline 5 & UFSC & Sul \\
\hline 5 & UFMG & Sudeste \\
\hline
\end{tabular}

Fonte: Dados da pesquisa.

*Independente foi o termo usado para indicar o periódico que não está ligado a nenhuma instituição. (Informação repassada pelo editor do periódico).

Ao analisar as instituições responsáveis pela publicação dos sete periódicos com maior índice de publicação, observa-se que o INES se destaca. O Instituto é responsável por dois dos periódicos com maior índice de publicação de artigos: Espaço e Arqueiro. Uma das possíveis causas desse destaque pode estar ligada ao papel relevante que a instituição tem na vida da Comunidade Surda brasileira. Trata-se de uma instituição promotora de "fóruns, publicações, seminários, pesquisas e assessorias em todo o território nacional", cuja longevidade remonta ao ano de 1856 (INSTITUTO, 2015).

A distribuição geográfica das instituições editoras no território nacional assinala um domínio da Região Sudeste, precisamente nos Estados do Rio de Janeiro, São Paulo e Minas Gerais. Essa constatação vai ao encontro dos dados do Sistema de Informações Georreferenciadas 
(GEOCAPES), que apontaram essa região como uma das principais no ranking de publicações indexadas nas bases internacionais. Além desse fator, o maior número de universidades também se localiza na região Sudeste.

Entre os cinco primeiros periódicos com maior publicação de artigos, o mais antigo data de 1967. Os quatro demais foram lançados a partir dos anos 90, sendo que dois surgiram nos anos de 2000 e 2003. Essa ocorrência demonstra que os periódicos mais antigos tendem a publicar mais. Cabe ressaltar que os periódicos Espaço e Arqueiros, com grande concentração de artigos, ambos publicados pelo INES ${ }^{2}$, não são indexados em várias bases que são disponibilizadas pelo Portal de Periódicos da CAPES.

Entre 1987 a 2014, foram publicados 241 artigos. A distribuição cronológica dos artigos é representada na Tabela 6.

Tabela 6 - Distribuição cronológica da publicação dos artigos

\begin{tabular}{|c|c|c|c|c|}
\hline Período anterior & Quant. & Marco & Período posterior & Quant. \\
\hline ---- & --- & & $2002 *$ & 7 \\
\hline 1987 & 1 & & 2003 & 11 \\
\hline 1989 & 1 & & 2004 & 13 \\
\hline 1990 & 2 & \multirow{8}{*}{ 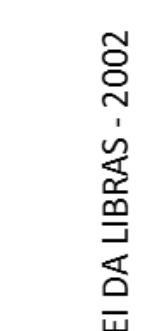 } & 2005 & 4 \\
\hline 1994 & 1 & & 2006 & 17 \\
\hline 1995 & 1 & & 2007 & 10 \\
\hline 1996 & 4 & & 2008 & 12 \\
\hline 1997 & 7 & & 2009 & 9 \\
\hline 1998 & 8 & & 2010 & 15 \\
\hline 1999 & 2 & & 2011 & 9 \\
\hline 2000 & 4 & & 2012 & 33 \\
\hline \multirow[t]{2}{*}{2001} & 8 & 悲 & 2013 & 31 \\
\hline & & & 2014 & 31 \\
\hline Total & 39 & & Total & 202 \\
\hline
\end{tabular}

Fonte: Dados da pesquisa.

Total geral: 241 artigos

* Considerando que não foi possível identificar o mês no qual os 7 artigos de 2002 foram publicados, optou-se por inseri-los no período posterior a Lei, já que a mesma foi promulgada no inicio do ano (abril).

No período anterior a promulgação da Lei, de 1987 a 2001, foram publicados 39 artigos o que corresponde a uma média de 3,5 ao ano. Nos anos posteriores à promulgação da Lei, de 2002 a 2014, foram publicados 202 artigos, média de 15,5 por ano.

Observa-se que a produção até 2002 era pequena. A partir de 2002 a produção científica em Libras ganha em quantidade e, espera-se em densidade. $O$ índice de aumento na publicação de artigos foi de $417 \%$ em relação ao período anterior a lei.

Esse aumento sugere que a promulgação da lei influenciou de forma positiva a produção de artigos científicos sobre o tema Libras, conforme pressuposto inicial dessa pesquisa.

2 O INES é reconhecido, na estrutura do MEC, como centro de referência nacional na área da surdez, exercendo os papéis de subsidiar a formulação de políticas públicas e de apoiar a sua implementação pelas esferas subnacionais de Governo. (INSTITUTO, 2015). 


\section{Considerações finais}

A opção da busca na Plataforma Lattes mostrou-se adequada para essa pesquisa, em grande medida por propiciar a identificação de artigos publicados em periódicos que não são normalmente indexados em bases de dados. Esse é o caso dos periódicos publicados pelo INES que é responsável por três dos periódicos com maior índice de artigos sobre Libras no período. Esse fato vincula-se ao desenvolvimento da temática Libras que no Brasil tem pouco tempo de pesquisa. A temática não conta ainda com a quantidade de pesquisa e de periódicos científicos especializados para sua maior visibilidade.

No que concerne à influência da legislação na produção científica, foi grande o aumento de artigos sobre o tema após a promulgação da lei de Libras. Essa expansão sugere um impacto positivo da legislação para o desenvolvimento área.

Contudo, analisou-se uma temática em formação no Brasil com apenas 16 anos de desenvolvimento da pesquisa, mas que vem apresentando características similares à de áreas consolidadas. A quantidade de artigos produzidas após 2002 é importante, pois representou um aumento significativo na produção de artigos em Libras. A formação de um núcleo de autores que produzem mais que a maioria dos outros autores é outro princípio observado em campos de pesquisa consolidados.

\section{Referências}

ALVARADO, R. U. A bibliometria no Brasil. Ciência da Informação, Brasília, v. 13, n. 2, p. 91-105, jul. /dez. 1984.

BRASIL. Lei n. 10.436 de 24 de abril de 2002. Dispõe sobre a Língua Brasileira de Sinais - Libras e dá outras providências. Diário Oficial [da] República Federativa do Brasil, Brasília, DF, 25 abril. 2002. Disponível em: $<<$ http://www.planalto.gov.br/ccivil 03/leis/2002/L10436.htm >. Acesso em: 21 out. 2015.

GARVEY, W.D. Communication: the essence of science. Oxford: Pergamon Press, 1979. p.127-147.

GUEDES, V. L. da S. A bibliometria e a gestão da informação e do Conhecimento científico e tecnológico: uma revisão da literatura. Ponto de Acesso, Salvador, v. 6, n. 2, p. 74-109, ago. 2012.

INSTITUTO NACIONAL DE EDUCAÇÃO DE SURDOS (INES). Produtos e serviços oferecidos pelo Instituto Nacional de Educação de Surdos. 2015. Disponível em: <www.ines.gov.br>. Acesso em: 13 jul. 2015.

NOGUEIRA, C. M. I.; ZANQUETTA, M. E. M. T. Surdez, bilingüismo e o ensino tradicional de Matemática: uma avaliação piagetiana. ZETETIKÉ: Revista de Educação Matemática, Campinas, v. 16, n. 30, p. 224, jul./dez. 2008. 
PRITCHARD, A. Statistical bibliography or bibliometrics?

Journal of Documentation, [s. I.], v. 25, n.4, p. 348-349, Dec. 1969

SANTANA, A. P.; BERGAMO, A. Cultura e identidade surdas: encruzilhada de lutas sociais e teóricas. Educ. Soc., Campinas, v. 26, n. 91, p. 565582, ago. 2005.

TAQUE-SUTCLIFFE, J. An intruction to informetrics. Information Proceessing and Management, v. 28, n. 1, p. 1-3, Jan. 1992.

VANTI, N. A. P. Da bibliometria à webometria: uma exploração conceitual dos mecanismos utilizados para medir o registro da informação e a difusão do conhecimento. Ci. Inf., Brasília, v. 31, n. 2, p. 152-162, maio/ago. 2002.

ZIMAN, J. Conhecimento público. São Paulo: USP, 1979. 